\title{
Making Room for Change through Rest
}

Margaret Heller

I write this column from the vantage point of my current role as a member of the Core Technology Section Leadership Team, and as a newly elected president-elect of Core, with my term starting in July 2021. The planning for Core began years ago but became a real division of ALA in the most chaotic of times. Visions for the first year of Core were set aside as we had to face the reality of all the work needing to be done remotely, without any conferences that would allow for in-person conversations, and with all the leadership and members under personal and professional strain. Yet being forced to start up slowly and deliberately provides some advantages. Settling into this new situation has allowed staff, leaders, and members to acclimate to a new division and learn how we want to do things in the future, rather than relying too much on how we did things in the past or feeling pressure to meet every demand.

Right now, we are all at a juncture in our personal and professional lives, and thinking about how to approach the coming months. Summer offers the promise of growth and reinvention. The pause that a break implies allows time for us both as individuals to make time for what is important to us, and as members or employees of institutions to reconsider our priorities. For people working in library technology, however, the "summer break" is often anything but. Public libraries become a hub for activity as schools are closed, and school and academic libraries may use slow periods when classes are not in session for necessary systems upgrades or to roll out a new service. The summer of 2020 was one of the most challenging of my life, both professionally and personally, and meeting all the demands of the moment left hardly any time for a true break. This year, just like last year, feels like a summer we might not let ourselves rest for a moment. While many libraries have been open to some degree over the past year, the upcoming summer has the potential for a return to something like normal. Shutting down regular in-person services and buildings felt chaotic since it required new ways of providing those services and building up new technical infrastructure, but without us having expected this in advance like a normal summer project. The return may also feel chaotic, but rather than approaching it as a series of tasks in a plan that requires lots of energy and work, I hope we can treat the time as a period of reflective practice and give ourselves time to understand what has changed.

Adapting to the realities of life since spring of 2020 has changed us all in various ways, and so too our library users have new needs and expectations. In some cases, they have embraced new services, though this has not been a smooth process for everyone. I have a family member who started using an e-reader for the first time during the pandemic to access library e-books when her public library was closed or had limited services. She was grateful for the option to access books this way, but occasionally struggled to follow the complex workflow from library app to vendor site to device. Without the ability to visit a physical reference desk to ask for help, she asked me to assist with device troubleshooting on several occasions. That worked well for her, but

Margaret Heller ( and (as of July 1, 2021) President-elect of the Core: Leadership, Infrastructure, Futures division of ALA. (C) 2021. 
not everyone has a digital services librarian in their quarantine bubble. I share this to illustrate that while some people will have adapted or gotten the help they need, for many, this time has been one of doing without or maladaptation. Going back to "normal" will not help those who will need even more than they did pre-pandemic. Taking time to understand that fact, and to accept that it will not be a quick process of return for many people, will allow us to give each other space to find a way back to our lives as library users and library employees.

While many of us feel uncomfortable when we see slow progress-I know I do-I am coming to realize the value of making space for slowness and for rest. Rest comes in all forms. It could be physical rest, but it could be pursuing an artistic or athletic hobby, intentional social interactions, or spiritual practices. Institutions might give extra time off or set healthy expectations for work hours and meeting-free days, while also discarding old practices and attitudes to create better future work environments. There are crises to which we must immediately react and respond, but without personal and institutional energy in reserve, we will not do as good a job when they occur. Crises include political upheaval, public health emergencies, and other major events, but we can also appreciate how they unfold on a more mundane level. Information technology work often requires odd hours, intense bursts of energy to complete projects in a small window of time, and unpredictable problems that require dropping everything else to address an emergency. It is natural to constantly look towards the most urgent and the newest problem. This tendency results in lengthy backlogs for requests and accumulates technical debt from deferred maintenance or refactoring. Yet as we bring our libraries and other institutions out of pandemic mode over the next few years, allowing for reflective space can help us to be cautious about the choices we make. For example, during earlier stages of the pandemic, many of us probably had to set up systems for some type of surveillance to maintain social distancing and aid in contact tracing. Taking some time to review all those new procedures and systems - and purposefully dismantle those with negative privacy implications-will help us to go forward as more ethical and empathetic institutions.

Taking it slow is going to be the only way through the next period. Summer 2021 should be about reflection on collective trauma. We responded to the events of the past year, whether it was for closing libraries, keeping libraries open as safely as possible, racial justice work, or election support, and now we must consider how to incorporate what we started into lasting change. To do that reflection will require rest. We know how important rest is but finding space for it is not usually a high priority. Rest allows us to integrate our experiences, and will build us back to make sure we can keep responding to what comes next. I am challenging myself to spend time in deliberate reflection at the cost of mindless productivity over the coming months so that I can keep helping my library and Core succeed. I hope you will consider doing the same. 